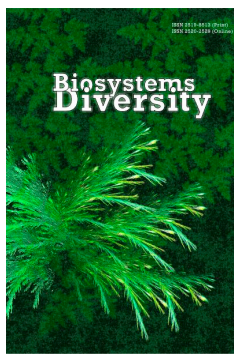

\title{
Agroeconomic and agroecological aspects of spatial variation of rye (Secale cereale) yields within Polesia and the Forest-Steppe zone of Ukraine: The usage of geographically weighted principal components analysis
}

\author{
O. M. Kunah*, O. Y. Pakhomov*, A. A. Zymaroieva**, N. I. Demchuk***, \\ R. M. Skupskyi****, L. S. Bezuhla***, Y. P. Vladyka**** \\ *Oles Honchar Dnipro National University, Dnipro, Ukraine \\ **Zhytomyr National Agroecological University, Zhytomyr, Ukraine \\ ***Dnipro State Agrarian and Economic University, Dnipro, Ukraine \\ ****Mykolayiv Inter-Regional Institute of Human Development of the Institute of Higher Education "Open International University \\ of Human Development "Ukraine",", Mykolayiv, Ukraine
}

Article info

Received 24.09.2018

Received in revised form 07.11.2018

Accepted 10.11.2018

Oles Honchar Dnipro National University Gagarin av., 72, Dnipro, 49000, Ukraine. E-mail: kunah_olga@ukr.net

Zhytomyr National Agroecological

University, Stary blvd., 7,

Zhytomyr, 10008, Ukraine.

E-mail:nastya.zymaroeva@gmail.com

Dnipro State Agrarian and Economic

University, Sergey Yefremov st., 25 ,

Dnipro, 49600, Ukraine.

E-mail:natademchyk@gmail.com

Mykolayiv Inter-Regional Institute of Human Development of the Institute of Higher Education "Open International

University of Human Development

“Ukraine",", 2nd Viiskova st. 22,

Mykolayiv, 54003, Ukraine.

E-mail: skuruslan@gmail.com
Kunah, O. M., Pakhomov, O. Y., Zymaroieva, A. A., Demchuk, N. I., Skupskyi, R. M., Bezuhla, L. S., \& Vadyka, Y. P. (2018). Agroeconomic and agroecological aspects of spatial variation of rye (Secale cereale) yields within Polesia and the Forest-Steppe zone of Ukraine: The usage of geographically weighted principal components analysis. Biosystems Diversity, 26(4), 276-285. doi:10.15421/011842

In the present article, the patterns of the geographic variability in yields of rye within Polesia and the Forest-Steppe zone of Ukraine are presented and the correlation of the factors and dynamics of an agroeconomic and agroecological nature was determined. The dynamics of rye yields in the study area over time were determined as being characterized by three extreme points: two local maxima and one local minimum. Specific terms of the polynomial curve of the fourth order can be meaningfully interpreted and applied to describe the dynamics of productivity. Free members of the polynomial indicate culture productivity in the starting period. Dynamics of the productivity that can be explained by the regression indicate that agrotechnological and agrecological conditions of agricultural production are a pervasive factor that determines the presence of a general trend. The determination coefficient of the regression total trend can be interpreted as an indicator of the role of the agrotechnological and agroeconomic factors in the dynamics of productivity. The residue of the trend regression model can be interpreted so as to include the agroecological component of the rye yields dynamics. Their analysis revealed seven key components that together explained $58.4 \%$ of the total variability of the space feature. The principal components of vibrational patterns reflect the specific nature of variation of rye yields over time, which are spatially defined. Vibrational effects are environmental in nature. Geographically weighted principal component analysis showed the transience of environmental spatial modes which determine the oscillating component of rye yield variation over time. Spaces within which the structure of ecological interactions remains unchanged can be considered as the basis of agroecological zoning areas.

Keywords: geographically weighted principal component analysis; yield; rye; spatial variability; temporal dynamics

\section{Introduction}

There is an urgent need to increase the production of quality agricultural products (Godfray et al., 2010; Tscharntke et al., 2012) due to the steady trend of increase in the global human population (Godfray et al., 2010). Agricultural production takes place in conditions of global climate change and the growing pressure on natural ecosystems (Bohan et al., 2013). The influence of the climate change also affects the variability in the yield of crops and human needs in food (Li, 2015). The average surface temperature is a key indicator of climate change. Substantiated evidence indicates that the global average temperature has increased by $0.90 \pm$ $0.05^{\circ} \mathrm{C}$ since mid- 1950 and will increase by another $1-3{ }^{\circ} \mathrm{C}$ by the end of this century (Hansen et al., 2010; Rohde, 2013). The level of the carbon monoxide significantly increased over the last century and there is a strong link between global warming and the level of greenhouse gases in the atmosphere (Canadell et al., 2007). It is expected that climate change will be manifested in the increase in global average temperatures, changes in precipitation patterns and increase in the frequency and severity of extreme weather events (Cai et al., 2014).

Spatio-temporal variation of ecological processes can be decomposed into spatial and temporal components (Hammond \& Kolasa, 2014)
Synchrony and persistence are important components of spatial and temporal variability. When the yield of certain crops increases or decreases in the same year in each of two places, the culture of these places are in synchrony. On the other hand, the persistence manifests itself in the fact that the average yield is different in two locations or other spatial units $(\mathrm{Li}, 2015)$. Spatial patterns are diagnostic when they are used to uncover the hidden mechanisms in the landscape and predictive as they indicate the most probable future behaviour of processes (Hammond \& Kolasa, 2014; Maamar et al., 2018).

The main tenet of landscape ecology is the concept of the decisive influence of landscape patterns on ecological processes (Turner et al., 1989; Zhukov et al., 2013). Land degradation and ecological processes create potentially dangerous feedback (desertification, salinization) and provide a source of long-term negative impact on agricultural production (Rockstrom et al., 2009; Kharytonov et al., 2018). Yields of crops can be increased by improving agricultural technologies (Mueller et al., 2012) and crop genetics (Tester \& Langridge, 2010). But the effectiveness of these directions is limited by increasing costs associated with the risk of diseases and negative impact of pests (Oerke \& Dehne, 2004; Brygadyrenko \& Nazimov, 2015; Kunah \& Papka, 2016). Traditional management of pests and diseases increases crop yields, but has some drawbacks. 
Nonspecific effect of synthetic insecticides leads to the destruction of non-targeted groups of organisms and thus disrupt natural pest control mechanisms (Newsom, 1967; Metcalf, 1980; Zhukov et al., 2017).

Harvest crops are the result of interactions between genetic characteristics of plants, soil characteristics, farming and climatic conditions (Diacono et al., 2012). Combining analysis of the soil properties and parameters of the growth of crops can be effective in identifying areas with different potential productivity (Taylor et al., 2003; Fleming et al., 2004; Basso et al., 2011; Zhukov et al., 2015). Landscape management is essential for biodiversity conservation (Andrushenko \& Zhukov, 2016; Lindenmayer et al., 2008; Tscharntke et al., 2012). Aggregation of agricultural fields and the suppression of areas that are not cultivated, leads to the transformation of complex landscapes with a relatively high proportion of semi-natural habitats into in structurally simple landscape dominated by arable fields (Roschewitz et al., 2005)

Landscape structure is a key factor in maintaining biodiversity (Antrop, 2005; Zhukov et al., 2016; Zhukov \& Andryushchenko, 2017). Analysis of the spatial and temporal dynamics of the yields of grain and leguminous crops in Polissya and the forest-steppe zone of Ukraine showed the complex nature of the processes that it defines. A common feature of the change over time is the presence of a trend, which can be described by a polynomial of the fourth degree. The trend is seen as one that has an agroeconomic and agrotehnological origin (Zymaroieva, 2018). Cluster analysis of the dynamics of winter wheat yield in the administrative districts of Dnipropetrovsk region allowed us to identify geographically defined districts, forming spatially associated complexes. Temporal dynamics of winter wheat yield in the interaction of endogenous and exogenous environmental factors form the main principle of discovering these environmentally homogeneous areas (Zhukov et al., 2018). Examination of the dynamics of sunflower productivity in agricultural enterprises of Poltava region by its administrative areas for the period 1995-2016 made it possible to establish the role of spatial and agroecological component variations and complete agroecological zoning of the territory of Poltava region based on dynamic characteristics of sunflower productivity (Zhukov \& Ponomarenko, 2017).

The aim of the article is to establish patterns of the geographical variability of the yield of rye (Secale cereale L.) in Polissya and the foreststeppe zone of Ukraine and determine the ratio of the factors of dynamics of agroeconomic and agroecological nature.

\section{Material and methods}

Data on the yield of rye in Polissya and the forest-steppe zones were presented (www.ukrstat.gov.ua) by the State Statistics Service of Ukraine.
The information covers the period from 1991 till 2017. These are the nature of the average yields by administrative district. The territory covers 206 administrative districts of ten regions of Ukraine (Vinnytsia, Volyn, Zhytomyr, Kyiv, L'viv, Rivne, Ternopil, Khmelnytsky, Cherkasy, Chernihiv).

The statistical analysis was performed using the software Statistica 10 (StatSoft Inc., USA). Compliance with data analysis of principal components was evaluated by the Kaiser-Meyer-Olkina test (KMO). Calculations were performed by the library REdaS (Hatzinger et al., 2014) for the environment of the statistical calculations R (R Core Team, 2017). Principal Component Analysis (PCA) is a statistical procedure that is widely used in research data analysis (Pearson, 1901). This non-parametric method reduces the dimension of the database and thus makes it possible to identify some common patterns hidden in data. The Moran statistics (Moran, 1950) was applied to calculate the global spatial autocorrelation coefficient, which is similar to the Pearson correlation coefficient. Both statistics vary between +1.0 (indicates a strong positive correlation) to 0 (points to a random pattern) and to -1.0 (indicates a strong negative autocorrelation) (Iqbal et al., 2005). Moran global statistics were calculated (www.geoda.uiuc.edu) with the use of the program Geoda095i (Anselin et al., 2005). The method of the geographically weighted principal components analysis (GWPCA) was implemented with a package GWmodel for the environment of the statistical calculations $R$ (http://cran.rstudio.com).

\section{Results}

The analysis of the total trend. Typical dynamic averaged data of the rye yields in the study area is characterized by three extreme points: two local maxima and one local minimum. The dependence of the available three point extremes can be described using the polynomial of the fourth order (Zhukov \& Ponomarenko, 2017):

$$
Y_{x}=b+a_{1} x+a_{2} x^{2}+a_{3} x^{3}+a_{4} x^{4}
$$

where $Y_{x}$ is a rye yield at the time $x ; b, a_{1}, a_{2}, a_{3}, a_{4}$ are the regression coefficients. Specific terms of polynomial curve of the fourth order can be meaningfully interpreted and applied to describe the dynamics of rye yield (Fig. 1). Constant $\mathrm{b}$ indicates culture productivity in the starting period. If we assume that $x=0$ at the start of the study, then the constant will indicate the level of productivity at this time. It should be noted that the description of the actual dynamics of the selected analytic function is in a certain manner, a generalization and simplification. The form of the function and its parameters can be selected based on interpolation and there is no reason to use this feature to extrapolate - ie prospective or retrospective forecast.

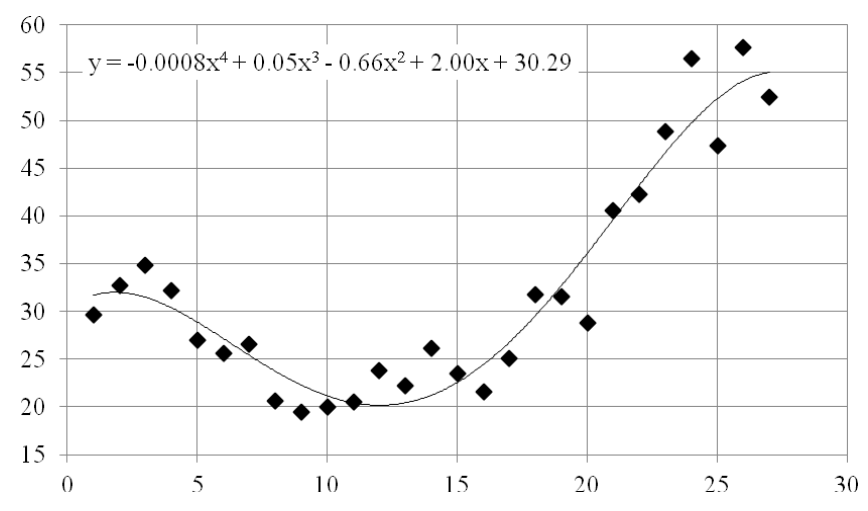

Fig. 1. Typical yields of rye dynamics for the years 1991-2017:

approximation and fourth order polynomial trend: here abscissa is the time (1 - 1991, $27-2017)$; ordinate is the yield ( $\mathrm{kg} / \mathrm{ha}) ; \mathrm{b}$ - constant of the polynomial equation; $\mathrm{Y}_{\mathrm{Min}}$ - polynomial value at the point of local minimum; $\mathrm{Y}_{\mathrm{Max}}$ - value of polynomial at the points of local maxima; $\operatorname{tg} \alpha$ - maximum speed of the crop increase in the time between the minimum and maximum, the tangent of the inflection angle of the tangent

line to the curve of the polynomial at the point of inflection (analagous to the maximum speed of reduction in yield in descending branch)

Moreover, the validity of these forecasts will be significantly reduced by increasing the time period for the prognosis is made. In addition, there is no reason to believe that even with a lag, which is the unit of measurement of time, the system does not change its properties significantly. Thus, the constant $\mathrm{b}$ indicates the starting conditions for the de- scription of the process and is an independent parameter of the temporal dynamics of crop yield changes over time.

Coordinates of the points of inflection function which describes the dynamics of yields of rye, can be found after solving the equation obtained as a result of differentiation of the polynomial of the fourth degree: 


$$
\mathbf{Y}_{x}^{*}=a_{1}+2 a_{2} x+3 a_{3}^{2}+4 a_{4}^{3} .
$$

Inflection points correspond to solving an equation that corresponds to the second derivative polynomial:

$$
\mathbf{Y}_{x}^{\prime \prime}=2 a_{2}+6 a_{3}+12 a_{4}^{2}=0
$$

The corresponding quadratic equation has two roots:

$$
x_{1,2}=\frac{-6 a_{3} \pm \sqrt{36 a_{3}^{2}-96 a_{4} a_{2}}}{24 a_{4}} .
$$

Substituting in the original equation regression the corresponding argument $\mathrm{x}_{1}$ and $\mathrm{x}_{2}$, we can distinguish the value that obtains the rate of change of productivity at these points, which are the maximum for the module. As the local maxima are located in areas close to the edges of the range of the studied period, their exact definition seems doubtful. In many cases, peaks are outside of the studied period. Therefore, the function of local maxima we do not apply as characteristic of the dynamics of rye productivity.

The rye productivity dynamics are described us via the constant, which reflects the initial conditions of soil fertility at the beginning of studied period and indicators the maximum speed of reduction in yields during the 1990s and the maximum rate of increase in productivity in the 2000s. Also the quality of description of the fourth order polynomial is characterized with the help of the coefficient of determination.

The coefficient of determination indicates the level of compliance of the model with real data and varies in the range of 0.56 to 0.91 (Fig. 2).

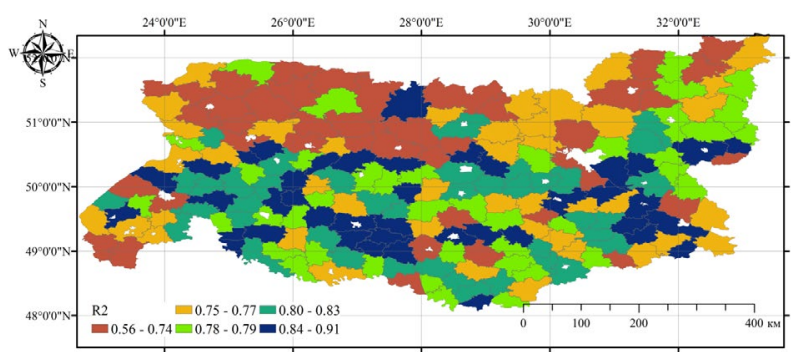

Fig. 2. Spatial variation of the coefficient of determination of the regression model

Polynomial regression has a global character. The existence of such a relationship occurs as a result of a constant external factor that affects the yield of crops. The nature of the overall dynamics of productivity that can be explained by the regression indicates that this factor is the agrotechnological and agroecological conditions of agricultural production. From this, the coefficient of determination can be interpreted as an indicator of the role of the agrotechnological and agroeconomic factors in the dynamics of productivity. The data indicate that these aspects of productivity are essential. The variation of the coefficient of determination is spatially dependent (I-Moran statistics is $0.14, \mathrm{P}=0.001$ ). The areas most sensitive to agrotechnological and agroeconomic factors are the southern, eastern and south-western areas of the region, and the least north. The starting level of rye productivity varies between $10.6 \mathrm{c} / \mathrm{ha}$ (northern and north-eastern regions) to $35.6 \mathrm{c} /$ ha (south and southeast) (Fig. 3). The variation of the initial rye yield is spatially dependent (I-Moran statistics is $0.46, \mathrm{P}=0.001$ ).

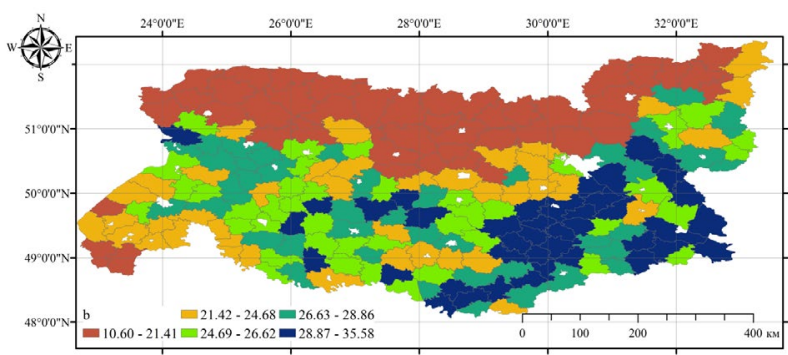

Fig. 3. Spatial variation of the level of rye yield in the starting period of research (const $b$ of the regression equation)

The regression coefficients of trend productivity models are strongly correlated with each other, indicating that the intensity of decreased yields (constant $\mathrm{a}_{1}$ ) is inversely proportional to the initial yield potential (constant $\mathrm{b}$, the correlation coefficient between $\mathrm{a}_{1}$ and $\mathrm{b}-\mathrm{r}=0.74, \mathrm{P}<$ 0.001 ), and the increased intensity in productivity in the second half of the study period is inversely proportional to the intensity of the previous decline (the correlation coefficient between $\mathrm{a}_{1}$ and $\mathrm{a}_{2} \mathrm{r}=-0.81, \mathrm{P}<$ 0.001 ). In order to assess the dynamics of the factors that are independent of the initial conditions, the regression analysis was conducted according to the parameters of trend parameters preconditions. For the regression parameters $a_{1}$ equation is:

$$
\mathrm{a}_{1}=-0.11 \pm 0.05-0.027 \pm 0.017 \mathrm{~b}, \mathrm{R}^{2}=0.54
$$

where $a_{1}$ - speed of the reduction in yields in the first period of the study as a result of evaluation of the total trend, $b$ - starting potential yield at the beginning of the studied period.

The dependence of two predictors was found for regression parameter $\mathrm{a}_{2}$ :

$\mathrm{a}_{2}=0.72 \pm 0.04-0.0079 \pm 0.0025 \mathrm{a}_{1}-1.08 \pm 0.068 \mathrm{~b}, \mathrm{R}^{2}=0.66$, where $\mathrm{a}_{2}$ - the rate of increase in productivity in the second period of the study, $a_{1}$ - the rate of yield decline in the first period of study on the basis of the evaluation of total trend, $\mathrm{b}$ - starting potential yield at beginning of the period studied.

In the further part of the article, the speed of the total reduction or increase in yields according to the established trend is described using the residuals of the regression models, which are independent of the parameters that characterize the particular dynamics of previous periods and thus have independent information.

The variation of the deviation from the dependence of the maximum speed of decrease in crop yield on the initial potential of crops is spatially dependent (I-Moran statistics is $0.08, \mathrm{P}=0.001$ ) (Fig. 4).



Fig. 4. Spatial variation of deviation from the dependence of maximum speed of reduction of the yield on the initial potential yield

Areas with a positive deviation (speed of decrease is slower than the overall trend dynamics) are concentrated in the east, northeast, northwest and center in some regions. In the southern and eastern parts deviation from the general trend is negative. In these regions, the decline was more intense than in the whole investigated area.

The variation of dependency of the maximum growth rate of the yield on the initial yield potential and maximum speed of decrease in yields is not spatially dependent (I-Moran statistics is $0.003, \mathrm{P}=0.410$ ). Visual studies of the map of spatial distribution of the indicator (Fig. 5) suggest that the dynamics of the rate of recovery of productive capacity is affected by a complex and nonlinear spatial pattern that cannot be quantified without sophisticated multiscale organization of this phenomenon. For its description PCNM-analysis (Zhukov et al., 2017) can be applied but this is beyond the scope of our study.

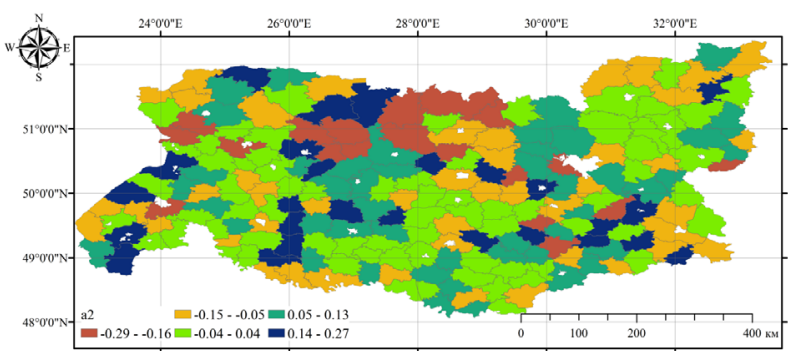

Fig. 5. Spatial variation of the residuals of the maximum growth rate $\left(a_{2}\right)$ regression from the initial yield potential $(b)$ and maximum speed of the yields decrease $\left(a_{1}\right)$ 
The global principal components analysis. Regression using fourthorder polynomial explains a significant part of the variance in yields of rye. In further analysis regression model residuals will be applied. These residuals are likely to also have a complex nature. Of course, this random noise associated with objective errors in the original data. Also in the regression residuals we can expect components associated with regular variation that may have an environmental nature.

The next question to be resolved before using principal component analysis is whether the sample size is large enough for statistical analysis. Is there some redundancy between variables? We investigated the yield in the 203 administrative districts in terms of 27 variables (years). The Kaiser-Meyer-Olkina index (KMO) was applied to the entire amount of data to determine the adequacy of the collected materials for the analysis of principal components. Since KMO is 0.68 , according to Kaiser's rules of thumb (Kaiser, 1974), study data should be recognized data suitable for principal components analysis.

Analysis of the principal component residuals regression model revealed that according to the Horn procedure (Horn, 1965) the statistically significant number of principal components is 7 (Table. 1). Taken together, the first seven principal components explained $58.4 \%$ of the total variability of the spatial feature. For further analysis by the scree test (Cattell, 1966), we selected the first three principal components that together explained $35.1 \%$ of the total variability of the spatial feature.

Table 1

Principal component analysis

\begin{tabular}{cccccc}
\hline $\begin{array}{c}\text { Principal } \\
\text { component }\end{array}$ & $\begin{array}{c}\text { Adjusted* } \\
\text { eigenvalue }\end{array}$ & Eigenvalue & Differences & $\begin{array}{c}\text { Variation } \\
\text { explained }\end{array}$ & $\begin{array}{c}\text { Standard } \\
\text { deviation }\end{array}$ \\
\hline 1 & 3.39 & 4.13 & 0.73 & 15.29 & 2.03 \\
2 & 2.22 & 2.84 & 0.62 & 10.54 & 1.68 \\
3 & 1.98 & 2.51 & 0.54 & 9.30 & 1.58 \\
4 & 1.36 & 1.82 & 0.46 & 6.74 & 1.35 \\
5 & 1.36 & 1.76 & 0.40 & 6.51 & 1.32 \\
6 & 1.04 & 1.37 & 0.34 & 5.09 & 1.17 \\
7 & 1.04 & 1.33 & 0.28 & 4.91 & 1.15 \\
\hline
\end{tabular}

Note: *-according to Horn procedure.

Variables used in the principal component analysis are the ordinal values - for years, so the loads of the principal component on the variables can be represented as dynamic change over time (Fig. 6). This form of representation allows meaningful interpretion of the extracted principal components as oscillatory processes of varying frequency. So, the principal component 1 describes $15.3 \%$ of the total variability of the yield of rye. It is characterized by a negative time autocorrelation with a lag of 1 and 11 years and positive autocorrelation with a lag of 12 years. Variation of principal component 1 has a clear spatial pattern (I-Moran is $0.16, \mathrm{P}=$ 0.001 ). Areas with high values of the principal component 1 form clusters in some areas to the east and north of the region (Fig. 7). Zones with reduced values of this principal component form a distinct cluster in the south-east from the center of the region. It should be noted that the meaning of the value of the principal components is conditional and it indicates only the consistency of the dynamics of productivity in the administrative areas. Accordingly, in the areas with the same value the productivity changes simultaneously, whereas the opposite sign points to the opposite direction.

The principal component 2 explains $10.5 \%$ of variability of the spatial feature and for its fluctuations the negative autocorrelation is typical with a lag of 2 and 9 years and positive autocorrelation with a lag of 11 years. The most typical is an oscillating process with a lag of four years. This component shows spatial patterns of variation (I-Moran statistic is $-0.07, \mathrm{P}=0.05$ ). Negative-Moran value indicates a spatial pattern which is caused by the attraction of areas with a higher value of the principal components to areas with the lowest and vice versa. Also for this principal component there is a clear trend towards decrease in the oscillation process during the study period.

The principal component 3 explains $9.30 \%$ of the variability epy rye yield and its characteristic oscillations with a period of 2-3 years. The high spatial level of the principal component 3 variation is confirmed by I-Moran statistics $(0.28, \mathrm{P}=0.001)$. Clusters of high values of the principal component 3 are typical for the northwest and southeast, and with low values - to the east and southwest. Thus, the global principal component analysis revealed the presence of dynamic processes of the rye yield of an oscillatory nature with varying frequency.
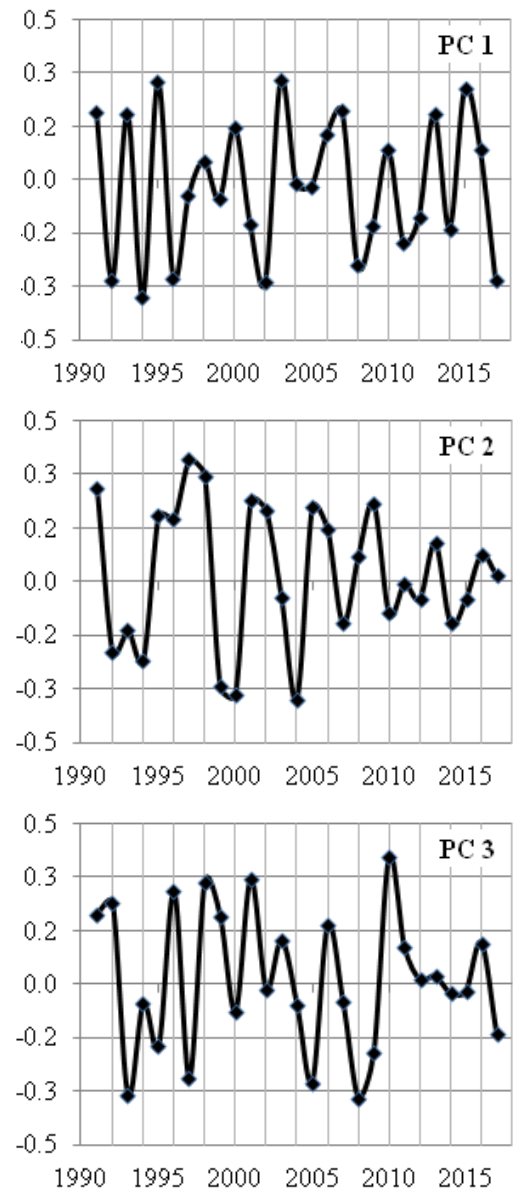

Fig. 6. The principal components 1-3 loads

Geographically weighted principal component analysis. The MonteCarlo test was conducted in order to establish whether the eigenvalues of the matrix data are characterized by a spatial component of the variation. As shown in Figure 8, the p-level for testing the standard deviation of the local's eigenvalues according to the results of the GWPCA is 0.01 . This value indicates that the hypothesis of spatial invariance of local eigenvalues can be with statistical probability rejected or otherwise, that there is a high level of spatial nonstationarity which presented in data on the yield of rye.

Before finding the optimal window of transmission, it is necessary to decide which number of principal components to leave out (Harris et al., 2011; Gollini et al., 2013). The results of the previous global analysis of principal components indicate that the first three components are able to explain together $35.1 \%$ of the variations in the structure of the data. Accordingly, the decision is justified to leave out three components for further GWPCA procedure.

The results of the procedure GWPCA can be visualized and interpreted by focusing on how the dimensions of the data in space are variable and on how the original variables affect the principal components. The percentage of spatial variation of total variation demonstrates clearly expressed variability, thus forming spatially homogeneous clusters in the Meridian direction (Fig. 9). Compared with the global analysis of the principal components, GWPCA demonstrates its effectiveness and efficiency in the analysis of spatial patterns of regional placement of rye yield by using the mapping of spatial variability of the principal components.

It was suggested that the variables with the biggest loads and intensity of their influence can be locally displayed (Lloyd, 2010). In the future we can show how each of the variables locally affect this component by mapping " the winning variables", i.e. those of which have the greatest absolute load. Figure 10 shows the spatial distribution of the variables with the greatest absolute load of the principal components GWPC 1-3 respectively. 

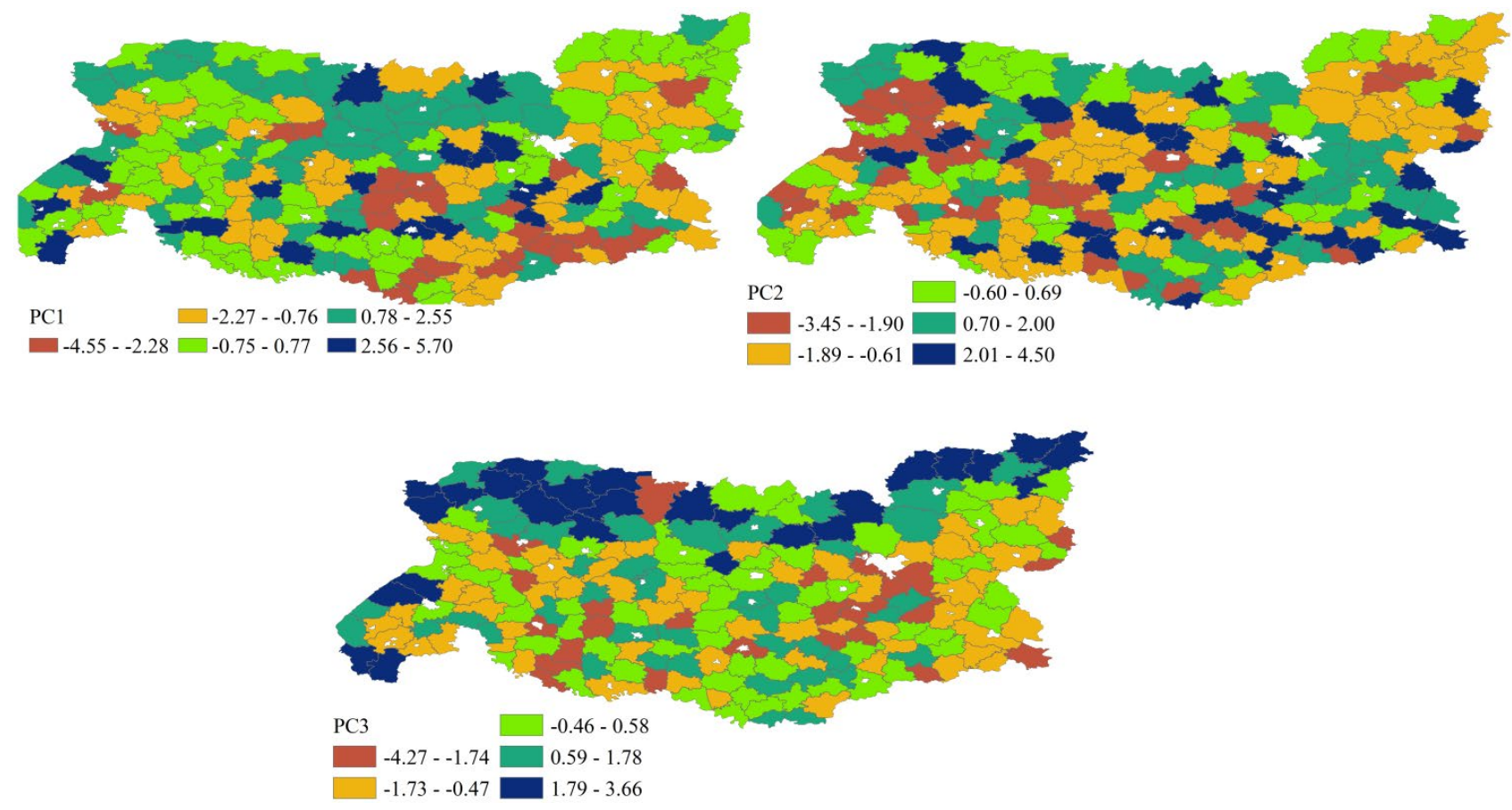

Fig. 7. Spatial variation of principal components 1-3

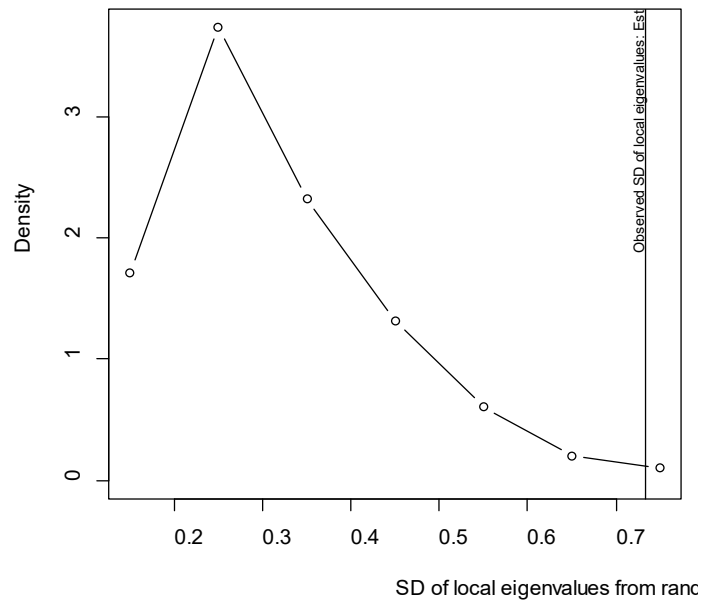

Fig. 8. Monte Carlo test for GWPCA

The largest absolute load of the variable, which are features of the spatial distribution of rye yield in a given year can be interpreted as a marker of the greatest sensitivity to the oscillatory dynamics over time, as was shown for the global principal component analysis. Local decisions can to a significant degree correspond to the global results, or differ in the significance of oscillatory processes at the regional level, which may cause a change in the order of components, or be expressed as a gain in statistical significance of processes which at the global level are not statistically significant.

The traditional presentation of "winning" variables for principal components cannot fully show the nature of the relationship between the dependent spatial indices that are measured by principal component analysis. The prevailing of the load factor is one aspect that characterizes the dynamics of rye yields. The oscillatory nature of this dynamic makes predominance the result of accidental release of the parameter at a specific time compared with the total recurring dynamics. Therefore, for each of the statistically significant principal components we performed a classification procedure of the administrative regions using cluster analysis based on distance, which is the inverse of the Pearson correlation coefficient. This indicator of distance is sensitive to the form of comparable indicators, rather than their absolute values. The specified approach allows us to identify groups of administrative districts which are characterized by similar temporal dynamics of rye yields in the relevant aspects of the principal components. We can assume that the aggregate administrative regions which are characterized by similar yield dynamics are also geographically close and form homogeneous ecological regions.

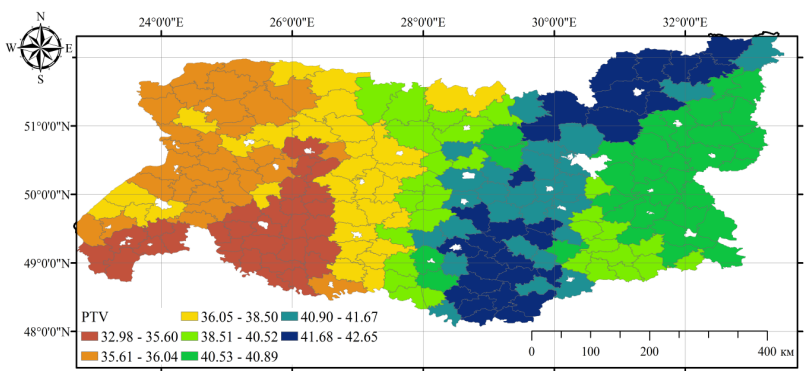

Fig. 9. Spatial variability of the percentage of total variance (PTV)

The cluster analysis of the administrative districts on the basis of the factor loadings GWPC 1 revealed three homogeneous clusters (Fig. 11). For each cluster we calculated the average values of factor loadings, which helped assess the specificity of the respective clusters (Fig. 12).

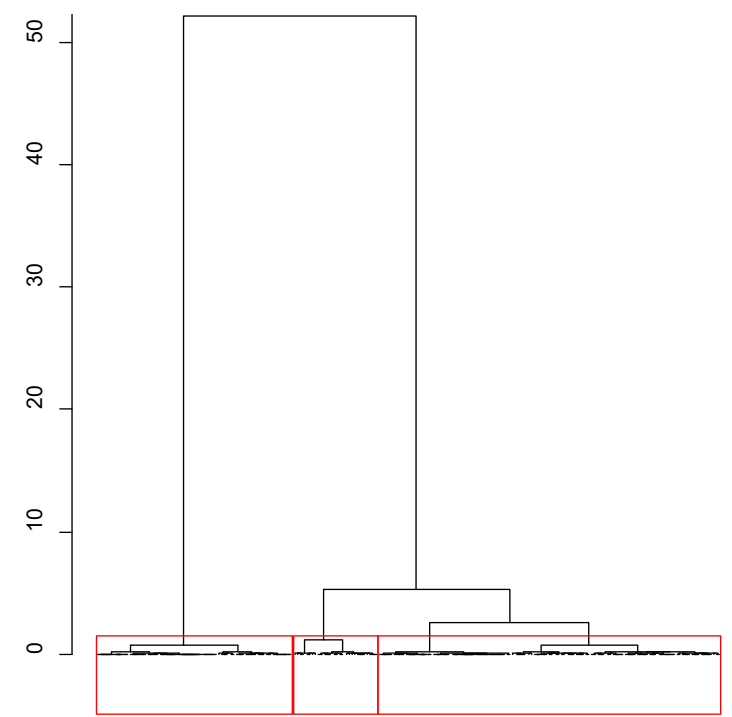

Fig. 11. Cluster analysis of administrative districts according to values of factor loadings GWPC 1 

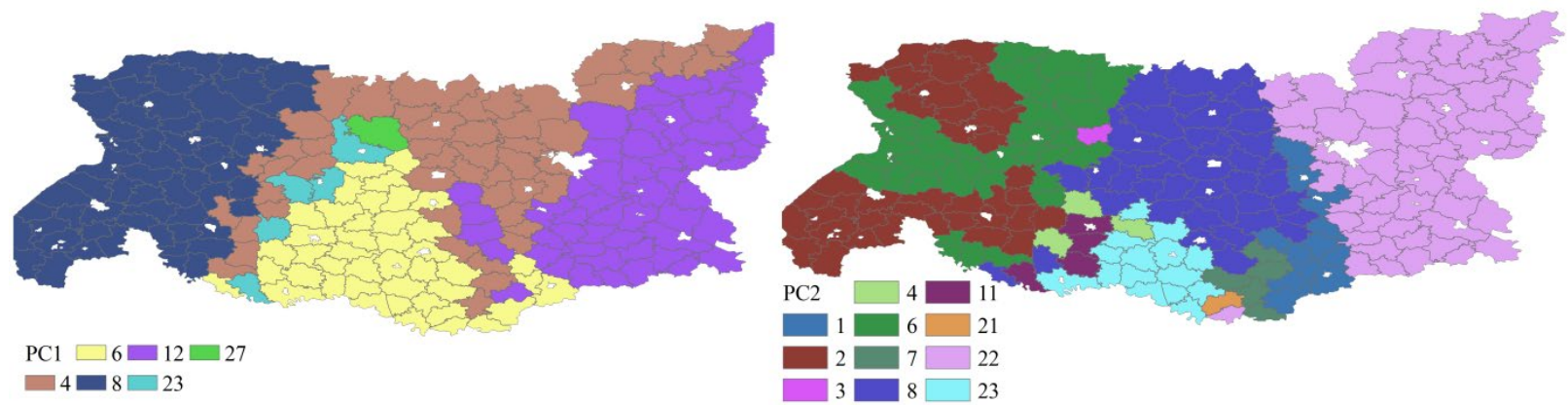

PC1 $\square 6 \square 12 \square 27$

$4 \square-23$

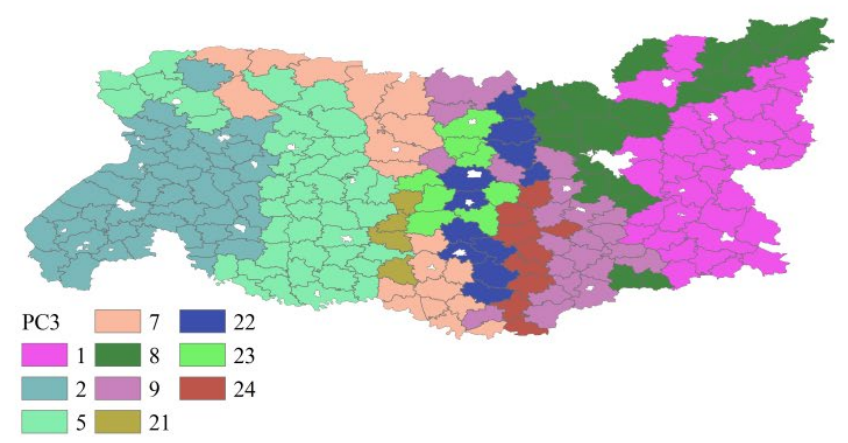

Fig. 10. Spatial placement of "winning" variables for the principal components 1-3

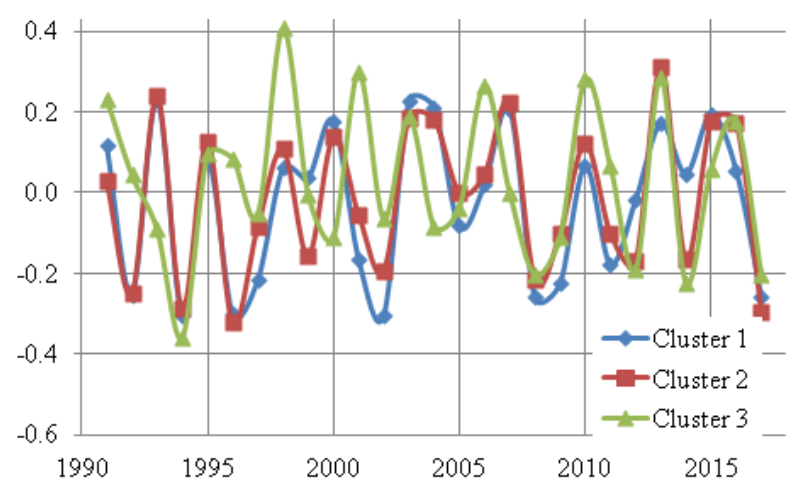

Fig. 12. The average values of factor loadings GWPC 1 for clusters 1-3: abscissa - the primary variable (residuals of regression models of yield trend for years), ordinate axis - factor loads

Established clusters and their distribution factor loadings give an idea of the course of processes that are characteristic of the respective cluster. General trends are quite similar variation for all clusters. The peculiarities lie in some shift in frequency and amplitude of variation in the period 1995-2005. Before this period and after the oscillatory processes in the clusters match the phase and are quite similar in amplitude. Obviously, the imbalance which took place at the level of agroeconomic and agroecological components in the 1990s showed itself in a different course of the production process. The specificity of the oscillatory processes clearly marked the spatial component (Fig. 13).

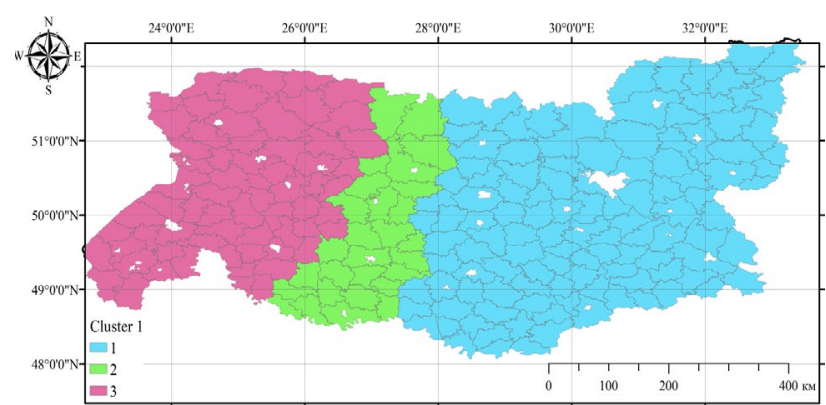

Fig. 13. Spatial distribution of clusters obtained on the basis of factor loadings GWPC 1
The spatial distribution of administrative districts included in the respective clusters is spatially regular (Fig. 13).

Cluster 1 covers the east and center of the study area. Cluster 3 shows the area located to the west and cluster 2 occupies the westerncentral position.

Cluster analysis of the administrative districts by the values of factor loadings GWPC 2 revealed three homogeneous clusters (Fig. 14). For each cluster we calculated the average values of factor loadings, which helped assess the specificity of the respective clusters (Fig. 15). For clusters 1 and 3, a decrease is characteristic during the studied period, while for cluster 2 fading amplitude was observed in the middle of the period of study. In the spatial aspect, these clusters divide the research area into almost three equal areas (Fig. 16): cluster loccupies the central area, cluster 2 occupies the eastern and cluster 3 the western part of the territory.

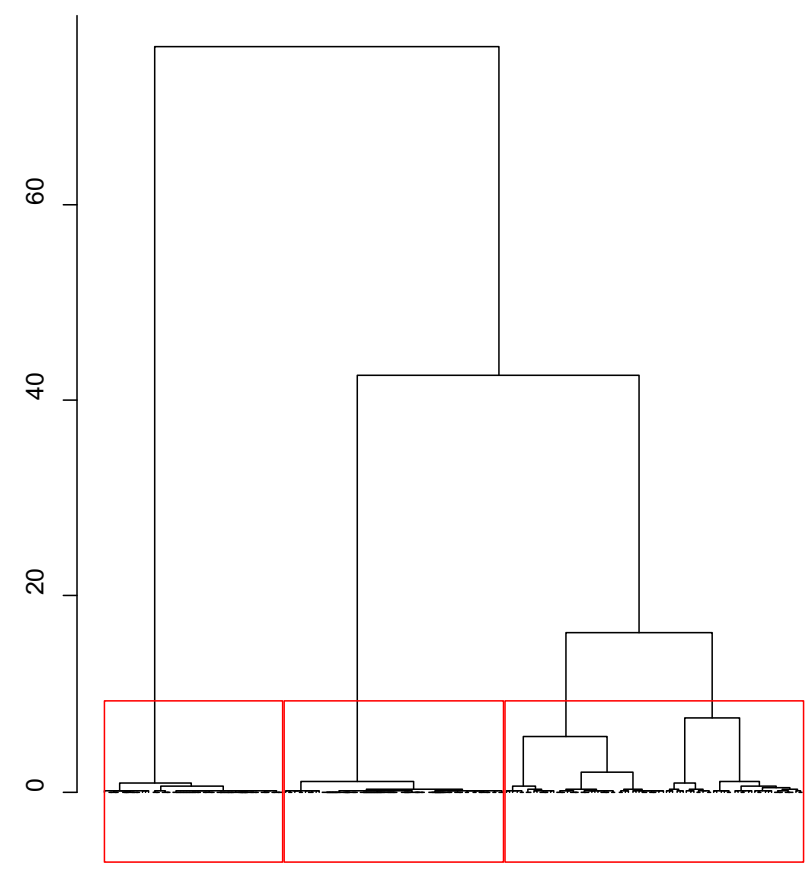

Fig. 14. Cluster analysis of administrative districts by values of factor loadings GWPC 2 


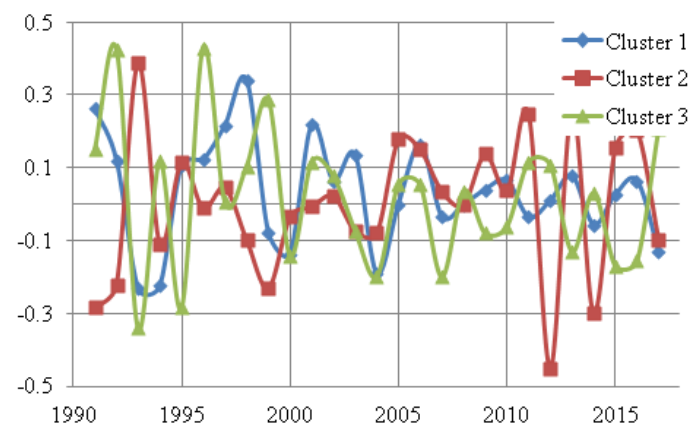

Fig. 15. The average values of factor loadings GWPC 2 for clusters 1-3: abscissa - the primary variable (residuals of regression models of yield trend for years), ordinate - load factor

Cluster analysis of the administrative districts by the values of factor loadings GWPC 3 revealed three homogeneous clusters (Fig. 17). For each cluster we calculated the average values of factor loadings, which helped assess the specificity of the respective clusters (Fig. 18). In terms of temporal dynamics, for cluster 2 a significant increase in amplitude at the end of the studied period (2011-2017) was characteristic, while for cluster 1 and 3 there is a tendency to decrease in amplitude throughout the period of study. Cluster 2 occupies the central part of the investigated area, and clusters 1 and 3 - to the east and west form a mosaic structure (Fig. 19).

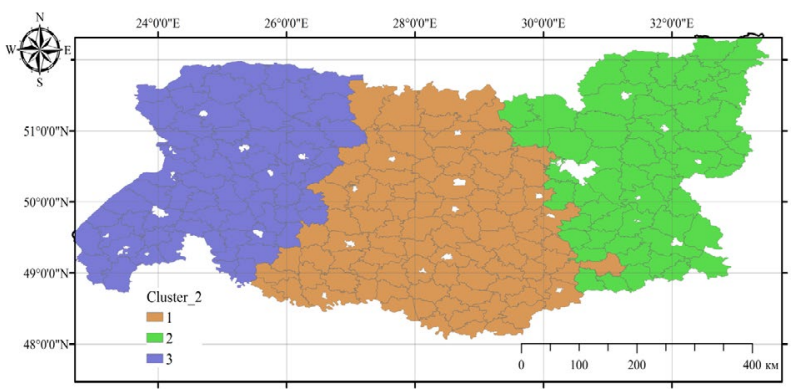

Fig. 16. Spatial distribution of clusters obtained on the basis of factor loadings GWPC 2

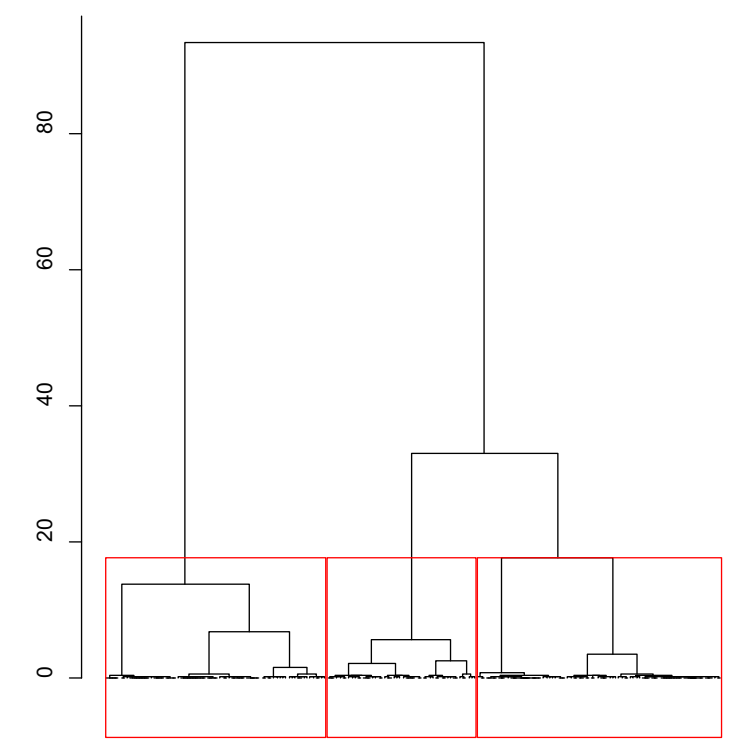

Fig. 17. Cluster analysis of administrative districts by values of factor loadings GWPC 3

\section{Discussion}

In the period 1991-2017 in Ukraine there were significant social and economic reforms initiated by the collapse of the Soviet Union and independence. Transformation of productive relations became a generator of a clearly marked trend of changes in the productive potential of agriculture (Zhukov \& Ponomarenko, 2017; Zhukov et al., 2018; Zymaroeva, 2018). This trend is associated with a sharp decline in production in the first half of the 1990s, following which the decline ceased and growth resumed, which reached its peak at the end of the 2000s. Such dynamics can quite well be described as polynomial. Three extreme points indicates that the fourth-order polynomial is the best mathematical model of the trend (Zhukov \& Ponomarenko, 2017). The coefficients of the models cannot be meaningfully interpreted, but on their basis it is possible to calculate the parameters that indicate the most characteristic properties of the trend dynamics. The free member of the polynomial - constant $b$ - indicates productivity of the culture in the starting period. The value of the function at the point of local minimum points indicates Ymin at the "trough" of the dynamics of the crop productivity. The nature of the trend we ascribe to agroeconomic and agrotechnological origin. The dynamics of the trend may be the nature of its economic cycle and its phases: rise, peak, decline, trough. The trough of the observed crop productivity coincided with the socio-economic crisis of the 1990s, which were a consequence of the process of disintegration of the USSR. Changes in forms of management and ownership of land, which became the main object of reforms in the agrarian sector of Ukraine, unfortunately, had a negative impact on soil fertility, which lost much of its humus - the world's most fertile black soil turned into soil of average fertility and continues to deteriorate. Restructuring of productive relations in agriculture and economic crisis led to a decline in agricultural technology of production. Of course, it directly affected the yield of crops.

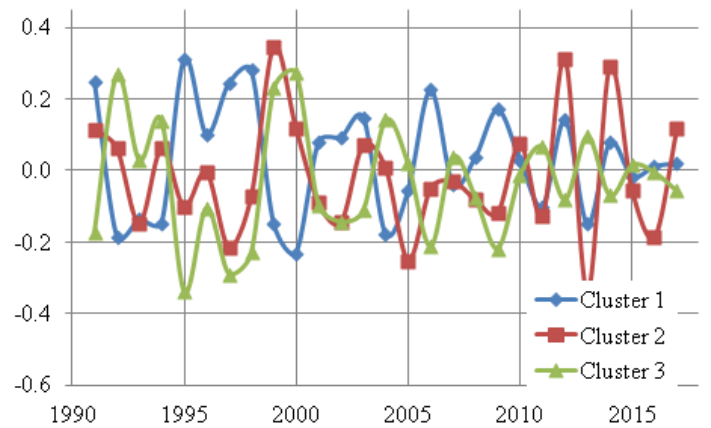

Fig. 18. The average values of factor loadings GWPC 3 for clusters 1-3: abscissa - the primary variable (residuals of regression models of yield trend for years), ordinate axis - load factor

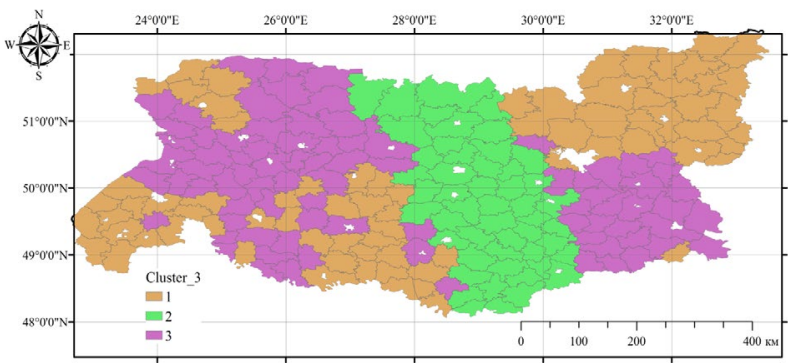

Fig. 19. Spatial distribution of clusters obtained on the basis of factor loadings GWPC 3

In the late 1990 's, the crisis in agriculture ended, and preconditions for sustainable development were being formed, which manifests in the almost linear increase in rye productivity up to the maximum parameter in the late 2010s. The condition of $Y_{\mathrm{Max}}$ maximum productivity culture reflects a balance between the factors of an agroeconomic and agrotechnological nature on the one hand and biological potential - on the other. Obviously, at such level of economic provision and agrotechnological system, farmland can provide greater yield. In this situation, the release of productivity on the plateau should be expected, yield variation on which would be conditioned not only by natural fluctuations which in origin are common both for natural and agricultural ecosystems. Instead of a plateau, yield reduction can occur, resulting in reduction of the local maximum. The reasons for yield decline after reaching a peak require 
separate research also in the economic sphere, but in our opinion, the reasons are chiefly of an agrotechnological nature. Irregularities in crop rotation lead to exhaustion of soil and loss of fertility, resulting in reduction of general level of yield of sunflower after local maximum.

Between the local maximum and minimum on the one hand and the minimum and maximum yield productivity on the other hand, the inflection point of the polynomial curve occurs, where the second derivative is zero. At these points the speed of reduction or increase in the crop reaches its maximum, and the corresponding dynamics can be approximated by a linear dependence. The angle of the tangent to the regression line at the intersection point indicates the maximum speed of reduction or increase in yield respectively, which may be a characteristic indicator of yield dynamics.

The dynamics of productivity in space and time is a trajectory in a multidimensional space, which significantly complicates its reflection and thus its research. Trend parameters can be calculated for each of the surveyed points in space, which are presented by geographic centroids of administrative districts. Features of the spatial variation of these parameters can be depicted cartographically. Thus, we have a possibility to cartographically reflect the spatial variability of parameters that indicate the peculiarities of the process dynamics over time.

Along with agroeconomic factors, agroecological factors may influence the formation of trendb. Agriculture is closely associated with the variability of climatic conditions and their changes. It can be expected that climate changes directly affect the production of agricultural crops. This impact can vary depending on the level of warming and changes in precipitation intensity, related to it (Kamran \& Asif, 2011). Climate variability significantly affects the fluctuations of crop yields. In some regions, more than $60 \%$ of yield variability over time of such crops as maize, rice, wheat and soybeans can be explained by climate variability (Ray et al., 2015). Various climate aspects (temperature and precipitation variability) may have different effects on growth of agricultural crops and their resulting yield (Urban et al., 2012). Such climatic variables as temperature and precipitation are significant factors in the spatial differentiation of yield (Ray et al., 2015). Reduction in yield following increase in temperature has been recorded all around the world (Lobell, 2007; Lobell et al., 2008). In Eastern Europe (including Ukraine), 23 $66 \%$ of interannual variability of yields can be explained by climate and normal or extreme temperatures (Ray et al., 2015). But the analysis of observations on crop yield of over time revealed a negative correlation between yield and temperature mainly only for maize. Both positive and negative correlation was determined for rice and wheat (Tao et al., 2008). Higher temperatures have a negative effect on yield of grain crops within different regions of Europe. Although food security in Europe is probably not much dependent on climatic conditions due to technologically developed agricultural practices (Brown \& Funk, 2008), climateinduced uncertainty (significant fluctuations) in the production of food as a result of an increase in temperature may occur in the future (Peltonen-Sainio et al., 2010).

Agroeconomic factors of the formation of the yield trend also have a complex nature. Differences in technological investments as well as agricultural technologies, such as the protection of plants, methods of seeding and use of fertilizers, can lead to differences in yield productivity (Annicchiarico \& Iannucci, 2008; Jensen \& Hauggaard-Nielsen, 2010; Flores et al., 2012). Spatio-temporal patterns include landscape systems and play an important role in the ecological dynamics of agricultural processes (Turner, 1990). Similarly to other ecological properties, yield demonstrates variability in space and time. Annual crop yield may vary between regions, which is the spatial variability (Mueller et al., 2012). The yield of a particular crop within the region is also inconstant from year to year, which is the temporal variability (Ray et al., 2015).

The presence of a trend, the mathematical form of which is unchanged, indicates the presence of permanent external factors which affect the process dynamic. We consider agroeconomic conditions of farming to be such a factor. But the final result of the impact is affected by factors of other nature, which have a local character. The remains of the trend model can be divided into two components: information noise impact and the outcome of regular factors. The latter most likely have an environmental origin if the fact that they are spatially structured is proven.
The analysis of the principal components of the model of temporal trend allowed us to determine three aspects of variability of rye yield within the studied territory, or the principal components. All of these components are spatially determined. In the dynamic aspect, these principal components are characterized by different frequency characteristics of variation over time. In addition, the principal component 2 was observed to have the tendency towards fading of the fluctuation process over time. It can be assumed that the agroeconomic crisis launched negative agroecological processes, and the stabilization of the production relations and the restoration of production contributed to the stabilization of the ecological situation in the agricultural spheres. Spatial variation of this factor can be linked with the centers of biological diversity, which are the basis of recovery of environmental stability and the surrounding landscape, including farmland.

Application of principal component analysis methods for the analysis of the dynamics of the yield is based on the supposed uniformity of the pattern of the relationships within all the studied area. Geographically weighted principal component analysis allows us to analyze the local patterns of dynamics of rye yield. Local models are more practical than the total model, which is quite natural for the consideration of local specifics can more objectively reflect the reality. But applying this approach raises some methodological difficulties for meaningful interpretation. The most common technique of mapping of "winning" variables is not applicable in the case of analysis of time series. Therefore, on the basis of close types of local dynamics, we determined the clusters for each principal component and used mapping of these clusters instead of demonstrating "winning" variables. This approach has some advantages.

First, the homogeneous areas ecologically obtained using our approach (Fig. 13, 16, 19) are more compact than the zones determined using "winning variables" (Fig. 10). This result is conditioned by the fact that in the formation of the clusters the predominant role belongs to the factors of a regular nature, and random factors are filtered out as a result of the analysis procedure. At the same time, the "winning variables" are the result of overall random selection of some informatively valuable variables. Therefore, both approaches generally give a similar picture, but the proposed algorithm is less sensitive to random factors.

Secondly, the suggested algorithm allows integrative interpretation of the clusters using the analysis of the dynamic peculiarities of each cluster over time. In the "winning variable" approach, the variable is the marker of the corresponding spatially uniform area. But such tool is acceptable at using qualitatively different variables, each of which can be measured in the next period of time and thus be used for the prediction of the studied phenomenon. Among the variables of time series, there are no "more important" or "less important" years. In addition, all these variables are retrospective and cannot be re-measured. For the prediction, the patterns based on the cyclic periodicity of the processes could be used. Such features can be determined for selected clusters.

\section{Conclusions}

Rye yield dynamics in the studied area over time are characterized by three extreme points: two local maxima and one local minimum. Specific points of the polynomial curve of the fourth order can be meaningfully interpreted and applied to describe the dynamics of yield. The free member of the polynomial indicates the yield productivity of the crop over the starting period. Dynamics of the yield productivity that can be explained by the regression indicates that agrotechnological and agroecological conditions of agricultural production are a total factor that determines the presence of a general trend. The coefficient of determination of the regression of total trend can be interpreted as an indicator of the role of agrotechnological and agroeconomic factors in the dynamics of yield productivity. The residual of the regression model of the trend can be interpreted as such, containing the agroecological component of dynamics of rye yield. Their analysis revealed 7 key components that together explained $58.4 \%$ of the total variability of the spatial feature. The principal components reflect the specific patterns of the fluctuating nature of the variability of rye yield over time, which are spatially determined. The fluctuating processes have an ecological nature. Geographically weighted principal component analysis showed 
the spatial non-stationary condition of the ecological regimes, which determine the fluctuating component of the variability of rye yield over time. The spaces within which the structure of ecological interactions remain unchanged, can be considered as the basis of agroecological zoning of territories.

\section{References}

Andrushenko, A. Y., \& Zhukov, A. V. (2016). Scale-dependent effects in structure of the wintering ecological niche of the mute swan during wintering in the gulf of Sivash. Biological Bulletin of Bogdan Chmelnitskiy Melitopol State Pedagogical University, 6(3), 234-247.

Annicchiarico, P., \& Iannucci, A. (2008). Breeding strategy for faba bean in Southern Europe based on cultivar responses across climatically contrasting environments. Crop Science, 48(3), 983-991.

Anselin, L., Ibnu, S., \& Youngihn, K. (2005). GeoDa: An introduction to spatial data analysis. Geographical Analysis, 38(1), 5-22.

Antrop, M. (2005). Why landscapes of the past are important for the future. Landscape and Urban Planning, 70, 21-34.

Basso, B., Ritchie, J. T., Cammarano, D., \& Sartori, L. (2011). A strategic and tactical management approach to select optimal $\mathrm{N}$ fertilizer rates for wheat in a spatially variable field. European Journal of Agronomy, 35, 215-222.

Brown, M. E., \& Funk, C. C. (2008). Food security under climate change. Science, 319, 580-581.

Brygadyrenko, V. V., \& Nazimov, S. S. (2015). Trophic relations of Opatrum sabulosum (Coleoptera, Tenebrionidae) with leaves of cultivated and uncultivated species of herbaceous plants under laboratory conditions. Zookeys, 481, $57-68$.

Cai, W., Borlace, S., Lengaigne, M., Van Rensch, P., Collins, M., Vecchi, G., Timmermann, A., Santoso, A., McPhaden, M. J., Wu, L., England, M. H., Wang, G., Guilyardi, E., \& Jin, F. F. (2014). Increasing frequency of extreme El Niño events due to greenhouse warming. Nature Climate Change, 4(2), 111-116.

Canadell, J. G., Le Quéré, C., Raupach, M. R., Field, C. B., Buitenhuis, E. T., Ciais, P., Conway, T. J., Gillett, N. P., Houghton, R. A., \& Marland, G. (2007). Contributions to accelerating atmospheric $\mathrm{CO}_{2}$ growth from economic activity, carbon intensity, and efficiency of natural sinks. Proceedings of the National Academy of Sciences, 104(47), 18866-18870.

Cattell, R. B. (1966). The scree test for the number of factors. Multivariate Behavioral Research, 1, 245-276.

Diacono, M., Castrignano, A., Troccoli, A., De Benedetto, D., Basso, B., Rubino, P. (2012). Spatial and temporal variability of wheat grain yield and quality in a Mediterranean environment: A multivariate geostatistical approach. Field Crops Research, 131, 49-62.

Flores, F., Nadal, S., Solis, I., Winkler, J., Sass, O., Stoddard, F. L., Link, W., Raffiot, B., Muel, F., \& Rubiales, D. (2012). Faba bean adaptation to autumn sowing under European climates. Agronomy for Sustainable Development, 32(3), 727-734.

Godfray, H. C. J., Beddington, J. R., Crute, I. R., Haddad, L., Lawrence, D., Muir, J. F., Pretty, J., Robinson, S., Thomas, S. M., \& Toulmin, C. (2010). Food security: The challenge of feeding 9 billion people. Science, 327(5967), 812-818.

Gollini, I., Lu, B., Charlton, M., Brunsdon, C., \& Harris, P. (2013). GWmodel: An $\mathrm{R}$ package for exploring spatial heterogeneity using geographically weighted models. Journal of Statistical Software, 63(17), 1-52.

Hammond, M. P., \& Kolasa, J. (2014). Spatial variation as a tool for inferring temporal variation and diagnosing types of mechanisms in ecosystems. PloS One, 9(2), e89245.

Hansen, J., Ruedy, R., Sato, M., \& Lo, K. (2010). Global surface temperature change. Reviews of Geophysics, 48(4), RG4004.

Harris, P., Brunsdon, C., \& Charlton, M. (2011). Geographically weighted principal components analysis. International Journal of Geographical Information Science, 25(10), 1717-1736.

Hatzinger, R., Hornik, K., Nagel, H., \& Maier, M. J. (2014). R: Einführung durch angewandte statistik (2nd ed.). Pearson Studium, München.

Horn, J. L. (1965). A rationale and a test for the number of factors in factor analysis. Psychometrika, 30, 179-185.

Iqbal, J., Thomasson, J. A., Jenkins, J. N., Owens, P. R., \& Whisler, F. D. (2005). Spatial variability analysis of soil physical properties of alluvial soils. Soil Science Society of America Journal, 69(4), 1338-1350.

Jensen, E. S., Peoples, M. B., \& Hauggaard-Nielsen, H. (2010). Faba bean in cropping systems. Field Crops Research, 115(3), 203-216.

Kaiser, H. F. (1974). An index of factorial simplicity. Psychometrika, 39(1), 31-36.

Kamran, A., \& Asif, M. (2011). Climate change and crop production. Crop Science, 51(5), 2299.

Kharytonov, M., Babenko, M., Velychko, O., \& Pardini, G. (2018). Prospects of medicinal herbs management in reclaimed minelands of Ukraine. Ukrainian Journal of Ecology, 8(1), 527-532.
Kunah, O. M., \& Papka, O. S. (2016). Ecogeographical determinants of the ecological niche of the common milkweed (Asclepias syriaca) on the basis of indices of remote sensing of land images. Visnyk of Dnipropetrovsk University. Biology, Ecology, 24(1), 78-86.

Kunah, O. M., \& Papka, O. S. (2016). Geomorphological ecogeographical variables definig features of ecological niche of common milkweed (Asclepias syriaca L.). Biological Bulletin of Bogdan Chmelnitskiy Melitopol State Pedagogical University, 1, 243-275.

Li, L. H. C. (2015). Assessing the spatiotemporal dynamics of crop yields and exploring the factors affecting yield synchrony. McMaster University, Hamilton, Ontario.

Lindenmayer, D., Hobbs, R., Montague-Drake, R., Alexandra, J., Bennett, B., Burgman, M., Cale, P., Calhoun, A., Cramer, V., Cullen, P., Driscol, D., Fahrig, L., Fischer, J., Franklin, J., Haila, Y., Hunter, M., Gibbons, P., Lake, S., Luck, G., MacGregor, C., McIntyre, S., Mac Nally, R., Manning, A., Miller, J., Mooney, H., Noss, R., Possingham, H., Saunders, D., Schmiegelow, F., Scott, M., Simberloff, D., Sisk, T., Tabor, G., Walker, B., Wiens, J., Woinarski, J., \& Zavaleta, E. (2008). A checklist for ecological management of landscapes for conservation. Ecology Letters, 11(1), 78-91.

Lloyd, C. D. (2010). Analysing population characteristics using geographically weighted principal components analysis: a case study of Northern Ireland in 2001. Computers, Environment and Urban Systems, 34(5), 389-399.

Lobell, D. B. (2007). Changes in diurnal temperature range and national cereal yields. Agricultural and Forest Meteorology, 145, 229-238.

Lobell, D. B., Burke, M. B., Tebaldi, C., Mastrandrea, M. D., Falcon, W. P., \& Naylor, R. L. (2008). Prioritizing climate change adaptation needs for food security in 2030. Science, 319, 607-610.

Maamar, B., Nouar, B., Soudani, L., Maatoug, M., Azzaoui, M., Kharytonov, M., Wiche, O., \& Zhukov, O. (2018). Biodiversity and dynamics of plant groups of Chebket El Melhassa region (Algeria). Biosystems Diversity, 26(1), 62-70.

Metcalf, R. L. (1980). Changing roles of insecticides in crop protection. Annual Review of Entomology, 25, 219-256.

Moran, P. A. P. (1950). Notes on continuous stochastic phenomena. Biometrika, $37(1 / 2), 17-23$.

Mueller, N. D., Gerber, J. S., Johnston, M., Ray, D. K., Ramankutty, N., \& Foley, J. A. (2012). Closing yield gaps through nutrient and water management. Nature, 490(7419), 254-257.

Oerke, E.-C., Dehne, H.-W. (2004). Safeguarding production - losses in major crops and the role of crop protection. Crop Protection, 23(4), 275-285.

Pearson, K. (1901). On lines and planes of closest fit to systems of points in space. Philosophical Magazine, 2(11), 559-572.

Peltonen-Sainio, P., Jauhiainen, L., Trnka, M., Olesen, J. E., Calanca, P., Eckersten, H., Eitzinger, J., Gobin, A., Kersebaum, K. C., Kozyra, J., Kumar, S., Marta, A. D., Micale, F., Schaap, B., Seguin, B., Skjelvåg, A. O., \& Orlandini, S. (2010). Coincidence of variation in yield and climate in Europe. Agriculture, Ecosystems and Environment, 139, 483-489.

R Core Team (2017). R: A language and environment for statistical computing. R Foundation for Statistical Computing, Vienna, Austria.

Ray, D. K., Gerber, J. S., MacDonald, G. K., \& West, P. C. (2015). Climate variation explains a third of global crop yield variability. Nature Communications, 6, 5989.

Rockstrom, J., Steffen, W., Noone, K., Persson, A., Chapin, F. S., Lambin, E. F., Lenton, T. M., Scheffer, M., Folke, C., Schellnhuber, H. J., Nykvist, B., de Wit, C. A., Hughes, T., van der Leeuw, S., Rodhe, H., Sorlin, S., Snyder, P. K., Costanza, R., Svedin, U., Falkenmark, M., Karlberg, L., Corell, R. W., Fabry, V. J., Hansen, J., Walker, B., Liverman, D., Richardson, K., Crutzen, P., \& Foley, J. A. (2009). A safe operating space for humanity. Nature, 461, $472-475$.

Rohde, R., Muller, R. A., Jacobsen, R., Muller, E., Perlmutter, S., Rosenfeld, A., Wurtele, J., Groom, D., \& Wickham, C. (2013). A new estimate of the average earth surface land temperature spanning 1753 to 2011 . Geoinformatics and Geostatistics: An Overview, 1, 1.

Roschewitz, I., Gabriel, D., Tscharntke, T., \& Thies, C. (2005). The effects of landscape complexity on arable weed species diversity in organic and conventional farming. Journal of Applied Ecology, 42, 873-882.

Tao, F., Yokozawa, M., Liu, J., \& Zhang, Z. (2008). Climate - crop yield relationships at provincial scales in China and the impacts of recent climate trends. Climate Research, 38, 83-94.

Tester, M., \& Langridge, P. (2010). Breeding technologies to increase crop production in a changingworld. Science, 327, 818-822.

Tscharntke, T., Tylianakis, J., Rand, T., Didham, R., Fahrig, L., Batary, P., Bengtsson, J., Clough, Y., Crist, T., Dormann, C., Ewers, R., Holt, R., Holzschuh, A., Klein, A., Kremen, C., Landis, D., Laurance, W., Lindenmayer, D., Scherber, C., Sodhi, N., Steffan-Dewenter, I., Thies, C., Van der Putten, W., \& Westphal, C. (2012). Landscape moderation of biodiversity patterns and processes - eight hypotheses. Biological Review, 87, 661-685.

Turner, M. G. (1990). Spatial and temporal analysis of landscape patterns. Landscape Ecology, 4(1), 21-30. 
Turner, M. G., O'Neill, R. V., Gardner, R. H., \& Milne, B. T. (1989). Effects of changing spatial scale on the analysis of landscape pattern. Landscape Ecology, 3, 153-162.

Urban, D., Roberts, M. J., Schlenker, W., \& Lobell, D. B. (2012). Projected temperature changes indicate significant increase in interannual variability of US maize yields. Climatic Change, 112(2), 525-533.

Zhukov, A. V. (2015). Phytoindicator estimation of the multidimensional scaling of the plant community structure. Biological Bulletin of Bogdan Chmelnitskiy Melitopol State Pedagogical University, 5(1), 69-93.

Zhukov, A. V., Andrusevich, K. V., Lapko, K. V., \& Sirotina, V. O. (2015). Geostatistical estimation of soil aggregate structure as a composite variable. Biological Bulletin, 3, 101-121.

Zhukov, A. V., Sirovatko, V. O., \& Ponomarenko, N. O. (2017). Spatial dynamic of the agriculture fields towards their shape and size. Ukrainian Journal of Ecology, 7(3), 14-31.

Zhukov, O. V., \& Ponomarenko, S. V. (2017). Spatial-temporal dynamics of sunflower yield - the ecological and agricultural approach. Ukrainian Journal of Ecology, 7(3), 186-207.
Zhukov, O. V., Ganzha, D. S., \& Dubinina, Y. Y. (2017). Remote sensing modeling of vegetation phylogenetic diversity spatial variation. Ukrainian Journal of Ecology, 7(2), 37-54.

Zhukov, O. V., Kunah, O. M., \& Dubinina, Y. Y. (2017). Sensitivity and resistance of communities: Evaluation on the example of the influence of edaphic, vegetation and spatial factors on soil macrofauna. Biosystems Diversity, 25(4), 328-341.

Zhukov, O. V., Pelina, T. O., Demchuk, O. M., Demchuk, N. I., \& Koberniuk, S. O. (2018). Agroecological and agroeconomic aspects of the grain and grain legumes (pulses) yield dynamic within the Dnipropetrovsk region (period 1966-2016). Biosystems Diversity, 26(2), 170-176.

Zhukov, O. V., Pisarenko, P. V., Kunah, O. M., \& Dichenko, O. J. (2015). Role of landscape diversity in dynamics of abundance of sugar beet pests population in Poltava region. Visnyk of Dnipropetrovsk University. Biology, Ecology, 23(1), 21-27.

Zymaroieva, A. A. (2018). Features of the spatiotemporal trend of grain and grain legumes yields in Forest and Forest-Steppe zone of Ukraine. Bulletin of Poltava State Agrarian Academy, 3, 66-73. 